\title{
The Effect of Semantic Clustering on the Acquisition of Quantitative and Qualitative Knowledge of Vocabulary
}

\author{
Mohammad Ali Heidari-Shahreza* \\ Department of English, Faculty of Humanities, Shahreza Branch, Islamic Azad University, Shahreza, \\ Isfahan, Iran \\ *E-mail address: maheidari.sh@gmail.com
}

\begin{abstract}
The present study explored the effects of semantic clustering on the acquisition of vocabulary knowledge. Two methods of vocabulary presentation (and instruction) were taken into account: a) Semantically-related presentation (SRP) which was based on the idea of presenting words in semantic clusters; and b) Semantically-unrelated presentation (SUP) which referred to presenting target words in unrelated sets. The results showed that the learners in the SRP class significantly outperformed their peers in the SUP class in both quantitative and qualitative measures of vocabulary knowledge.In-depth analysis of participants' score variations across levels of vocabulary knowledge also revealed that the SRP method of vocabulary presentation was probably a better facilitator in the learners' progress from a basic familiarity with the target words, to vocabulary knowledge at both reception and production level.The findings of the study are fully discussed and its pedagogical implications for language teachers are drawn upon.
\end{abstract}

Keywords: Semantic clustering; vocabulary knowledge; L2 vocabulary acquisition; EFL learners

\section{INTRODUCTION}

Learning a second or foreign language essentially entails learning a huge bulk of new words. Therefore, vocabulary knowledge (or lexical competence) is a part and parcel of L2 language proficiency (Hairrell, Rupley, \& Simmons, 2011). Moreover, the first years of child language acquisition is mainly centered upon lexical development (Ang, 2014). Likewise, the acquisition of new vocabulary is an ongoing task for EFL learners for years (Nation, 2013). Additionally, vocabulary knowledge is closely associated with language skills (i.e. linguistic competence) and learners' communicative competence (Heidari-Shahreza\&Tavakoli, 2012).

In recent years, second language acquisition (SLA) researchers have put forward competing definitions in an attempt to define and operationalize what knowledge of vocabulary incorporates (Rott, 2013). In this regard, some scholars tend to view such knowledge in dichotomous fashion by dividing it into receptive and productive aspects (Kieffer\&lesaux, 2012). Similarly, 'breadth' and 'depth' of vocabulary knowledge or 'quantitative' and 'qualitative' dimensions have been suggested to conceptualize the number of words a learner knows and how well he knows them (see for example, Heidari-Shahreza, Moinzadeh, \&Barati, 2014 a). Notably, Nation (2001) regards knowing a word at three macro levels of form, meaning and use. He also elaborates on these dimensions by suggesting a number of components at micro level to encompass different connotations and contextual 
nuances words manifest in authentic texts. In short, there is general consensus that various inter-related sub-knowledges amount to what is called vocabulary knowledge (Webb, 2013).

Research on the acquisition of vocabulary knowledge has revived in recent years to some extent thanks to the emphasis put on this strand of investigation by pioneer researchers and also due to the new insights recent studies have contributed to the existing literature (Webb, 2007). Along with this line of research, implicit and explicit approaches have been proposed by scholars to account for the acquisition of L2 vocabulary (see Choo, Lin, \&Pandian, 2012for a review). Proponents of implicit (or incidental) vocabulary acquisition regard written input (i.e. reading passages) and oral input as the main context of vocabulary acquisition and development (Heidari-Shahreza, 2014). In contrast, researchers working within an explicit perspective emphasize the role of input enhancement and instruction in developing lexical competence (Min, 2008). Despite ongoingdebates in favor of either approach, it is generally agreed upon that regardless of an implicit or explicit approach, presenting L2 vocabulary in an appropriate manner plays a significant role in the learners' uptake and vocabulary retention (Heidari-Shahreza, Moinzadeh, \&Barati, 2014 b).

\subsection{Semantic clustering}

The relevant literature suggests different possibilities in organizing and presenting new L2 vocabulary to EFL learners among which 'semantic clustering' has been the focus of attention in recent years(Finkbeiner\&Nicol, 2003). In simple terms, semantic clustering refers to the classification of words based on their meaning (Wilcox \& Medina, 2013). The underlying assumption is that words should be presented in groups which fall under the same hypernym (or superordinate concept). Therefore, words such as 'apple', 'banana', 'pear' and 'peach', for instance, are supposed to appear under the category of 'fruit'. Notably, the relevant literature indicates that semantic clustering is by far the most common manner of presenting new vocabulary in many available English textbooks where new words are classified under different categories (or semantic clusters, to be exact) such as 'body parts', 'leisure activities', 'occupation', 'sports', etc. (Wilcox \& Medina, 2013).

It is worth noting that semantic clusters differ from 'thematic' clusters in that the latter refers to organizing words based on their psychological associations and schematic affinity (Tinkham, 1997). Therefore, words such as 'restaurant', 'waiter', 'dinner', 'order' and 'tip' can be grouped as one thematic cluster based on the assumption that they all form a part of the schematic script, 'having dinner in a restaurant'. A distinctive feature of thematic clusters is that they most often include various word classes such as verbs, nouns and adjectives. Members of semantic clusters, in contrast, often have the same syntactic category(Wilcox \& Medina, 2013). Nevertheless, the distinction between these two types of clustering is not mutually exclusive and some words may be associated both semantically and thematically.

\subsection{Theoretical background of semantic clustering}

There are competing theories for and against presenting new vocabulary in semantic clusters (Erten\&Tekin, 2008). Most notably, semantic field theory(Lehrer, 1974) advocates such an approach to the organization and presentation of L2 vocabulary. This theory postulates that instead of a random storage, new words are stored in learners' minds based on the semantic interrelations and networks among them (Wilcox \& Medina, 2013). In other words, it is supposed that mind categorizes new vocabulary based on the connection strength exists between meaning(s) of the words. Hence, learners' mental lexicons contain numerous lexical networks (or semantic fields) which have been formed through the hypernymy of the concepts and semantic closeness of the words. Its pedagogical implication is that new 
vocabulary should be presented in semantic groups which resemble those of the learners' mental lexicon (Hashemi\&Gowdasiaei, 2005). In addition to semantic field theory, componential analysis(Nida, 1975), within the tradition of structural linguistics, also supports semantic clustering by emphasizing the importance of deconstructing words into their distinctive semantic features (or components). In other words, componential analysis puts forward the idea that once words' semantic components are derived, they became readily distinguishableso as to formsemantic groups accordingly.

Despite these supporting concepts on theoretical grounds, there also exist considerable debates against semantic clustering (Finkbeiner\&Nicol, 2003). Interference theory (Baddeley, 1990), for instance, asserts that when a series of new L2 vocabulary has too many semantic components in common and share the same semantic hierarchy, they interfere with one another. Subsequently, they compete for traces in memory to the effect that their acquisition and retention would be deterred (Nation, 2000). Therefore, interference theory recommends that new words not be presented in semantically-related groups particularly under the same superordinate concept. The distinctiveness hypothesis is also in line with interference theory in that it regards similarity an impeding factor for the organization of the concepts in mind (Hunt \& Elliot, 1980). This hypothesis posits that increasing the distinctiveness (or saliency) of information helps its better rendering and retention (Wilcox \& Medina, 2013). Therefore, unlike semantic field theory, it recommends new words be presented in nonrelated categories with an optimal distinctiveness.

\subsection{Empirical research on semantic clustering}

Research on semantic clustering originates from L1 studies on vocabulary acquisition and instruction. As Stoller and Grabe (1995) point outthese studies partially imply that presenting new vocabulary in semantic clusters might be conducive to better learning which isbased on the assumption that new information is attached to learners' established schemas. Therefore, they suggest new words should be presented semantically to activate relevant schemas and to be placed within their appropriate semantic networks.Finkbeiner and Nicol(2003) also acknowledge that, in spite of limited research on semantic clustering, L1 findings generally support this idea. Nevertheless, the possible effects of semantic clustering in SLA research has received little attention and as Wilcox and Medina note "There is little empirical evidence, however, that supports this claim in SLA, and only a handful of studies exist in this strand of research".

Tinkham (1993), for instance, found that advanced learners of English could learn unrelated sets of artificial words faster than pairs of semantically-related ones. Waring (1997) also in a similar study, concluded that hisparticipantswere $25 \%$ of the time likely to make errors in pairing words within the same semantic cluster (or superordinate concept). This percentage, however, fell to only $5 \%$ for nonrelated words. These two studies, therefore,implied a confounding effect for semantic clustering.

Finkbeiner and Nicol (2003) investigated the translation of semantically-related and unrelated words. The findings revealed that semantically-related words took statistically longer time for the participants in both forward and backward translation (i.e. L1-L2 and L2L1). They reasoned that the formation of the same lemma for semantic clusters caused interference and deterred translation in both directions. Papathanasiou (2009)also explored the impact of semanticclustering immediately and after a two-week delay through a translation task. She found that Elementary learners remembered significantly less semantically- related words regardless of time of assessment (immediately or delayed). Similarly, Erten and Tekin (2008) reached the same in an image-vocabulary matching test with a group of Turkish EFL learners at an elementary level. Finally, Wilcox and Medina (2013), investigated semantic and 
phonological clustering effects among 32 novice learners of L2 Spanish. The findings indicated that the semantically-clustered words were more difficult to learn.

While these studies provided evidence against semantic clustering, Schneider et al. (2002) reported that the participants significantly performed better in translating semantic clusters from L2 French to L1 English. There was, however, nosignificance difference between related and unrelated words in translation from English to French (i.e. L1-L2) which suggests that the impact of semantic clustering was only partial. Another study which gives more evidence in favor of semantic clustering is that of Hoshino (2010). Hoshino compared and contrasted five different types of lexical clustering: synonyms, antonyms, category, thematic, and unrelated. She concluded that categorical (i.e. semantic) clusters caused less difficulty for EFL Japanese learners.Most notably, Hashemi and Gowdasiaei (2005),reported that Iranian EFL learners were more successful in the acquisition of semantic sets based on both measures of depth and breadth of vocabulary knowledge.

As the above review of the relevant literature suggests, previous studies on semantic clustering have bored mixed results, for and against this type of vocabulary presentation. Moreover, the context of these studies (EFL or ESL, L1 or L2), participants' age and language proficiency have not always kept under control. In addition, as Wilcox and Medina (2013) point out, the number of target words per set in some of the studies is limited. Tinkham (1993) and Waring (1997), for instance, employed three and six semantically related words per setrespectively which does not seem sufficient. Finally, investigating the impact of semantic clusters together with other lexical groups such as thematic or phonological in some of these studies as in Hoshino (2010) and Wilcox and Medina (2013) makes any interpretation unwarranted due to the their possible interplay. Therefore, exploring the possible effects of semantic clustering on the acquisition of vocabulary knowledge still seems promising.

\section{THIS STUDY}

Given the above-mentioned gaps in the literature, the present study through a quasiexperimental design explored the possible effects of semantic clustering on the acquisition of vocabulary knowledge by Iranian EFL learners. In so doing, following Hashemi and Gowdasiaei (2005), two methods of vocabulary presentation (and instruction) were taken into account: a) Semantically-related presentation (SRP, hereafter) which was based on the idea of presenting words in semantic clusters; and b) Semantically-unrelated presentation (SUP, hereafter) which referred to presenting target words in unrelated sets. The following research question and null hypotheses guided the study:

Research question:

What are the possible effects of semantic clustering on the acquisition of L2 vocabulary knowledge by Iranian EFL learners?

Hypothesis 1: The participants will not acquire knowledge of the target words through SRP method.

Hypothesis 2: The participants will not acquire knowledge of the target words through SUP method.

Hypothesis 3: There will be no significant difference between the SRP and SUPparticipants in their acquisition of vocabulary knowledge. 


\subsection{Participants}

The population was young adult EFL learners. Through a convenience sampling, 50 participants including a roughly equal number of males and females took part in this research.They all had started learning English from the first grade in junior high school and had thus been learning English for about six years at the time of the study with an average age of 19.5. To ensure the appropriateness of the participants, first, the Oxford Placement Test was administered to 75 EFL learners at a language institutebased on which 57 were determined to be at intermediate level. Secondly, through Wesche and Paribakht's (1996) Vocabulary Knowledge Scale (VKS), the participants' homogeneity in terms of their vocabulary knowledge was assured. Afterwards, half of the participants (i.e. 25 learners) were assigned to the SRP class where they were to receive instruction via semantic clusters and the other half were put into SUP class to receive the target words in unrelated sets. The participants were also informedthat their participation in this study was totally voluntary and thatleaving the study would not result in any penalty or affect their relationship with their instructors at the institute.

\subsection{Materials and instruments}

The following material and instruments were employed to conduct the study:

\subsubsection{Target words}

Following Hashemi and Gowdasiaei (2005), one hundred target words (TWs, hereafter) from various semantic clusters were selected for instruction in the present study. To make sure the instruction could encompass both breadth and depth of vocabulary knowledge (quantitative and qualitative dimensions), the TWs were presented in short sentential contexts. This way, the participants had a chance to acquire an acceptable range of denotative and connotative meanings of the TWs. Both SRP and SUP learners were instructed the same vocabulary items in identical contexts. The only difference was that the SRP group received the TWs insemantic clusters under particular topics (or hypernym), whereas the SUP group received them randomly without any distinct organization.

\subsubsection{Measurement tools}

As mentioned, to discern the participants' general level of language proficiency, Oxford Placement Test was given. This test included 50 multiple choice questions which measured learners' knowledge of key grammar and vocabulary, a reading passage with 10 graded comprehension questions and a writing task that tested theparticipants' ability to produce the language.Vocabulary Knowledge Scale (VKS) test was also employed toassess the participants' quantitative and qualitative knowledge of the 100 TWs. In this test, the learners were asked to indicate their level of knowledge for each TW on a five-point scale which ranged from no familiarity with the word to knowledge at both receptive and productive level (see Table 1a). As for the scoring procedure, following Wesche and Paribakht (1996), levels 1 and 2 had oneand two points, respectively, and levels3-5 of vocabulary knowledge valued two to five points for the participants if they were able to provide evidence for their claimed knowledge via their given answer (see Table 1b). Since both quantitative and qualitative knowledge of vocabulary was in focus, the sum of each participant's scores for all the TWson the test was regarded as his/her qualitative knowledge. However, following Hashemi and 
Gowdasiaei (2005), to assess the students' quantitative knowledge of the TWs, scores 3, 4, and 5 were assigned one point each but scores 1 and 2 did not receive any point.

Table 1a. VKS Self-report Levels of Knowledge.

\begin{tabular}{cc}
\hline Level of knowledge & Learner's Self-report \\
\hline 1 & I don't remember having seen this word before. \\
2 & I have seen this word before, but I don't know what it means. \\
3 & I have seen this word before, and I thinkit means ----------: \\
4 & I knowthis word. It means ---------- (synonym or translation). \\
5 & I can use this word in a sentence: --------- (Write a sentence. \\
\end{tabular}

Table 1b. VKS Scoring Blueprint (Wesche \& Paribakht, 1996, slightly modified).

\begin{tabular}{cc} 
Level of knowledge & $\begin{array}{c}\text { Possible } \\
\text { score }\end{array}$ \\
\hline
\end{tabular}

\subsection{Procedure}

Having determined as appropriate intermediate EFL learners through Oxford Placement Test, the participants were randomly assigned to either SRP or SUP treatment group. About one week prior to the instruction phase, the participants took the 100-item VKS as the pretest. Afterwards, two 90-minute sessions were held to instruct the $100 \mathrm{TWs}$ for either treatment group during one week with a three-day interval between the sessions. In SRP class, the teacher presented the $100 \mathrm{TWs}$ in semantic clusters which were preceded by appropriate topics to introduce their semantic domain.In addition, each TW appeared in a sentence to clarify its appropriate use. Having read each sentence, the teacher asked the learners to repeat the TW and try to guess its meaning, based on the topic and the context in which it appeared. The teacher, then, provided the correct definition in English using appropriate synonyms and simple examples. If necessary, a Persian translation of the TWs was also given.

The same teaching method was followed in SUP class. The participants, however, did not receive the TWs in semantic clusters. Rather, the teacher taught them the words in a random manner. Since the TWs were not preceded by topics, the participants could only guess the meaning of the words through contextual clues. Thus, they were less successful in this regard. Nevertheless, the teacher provided them with the correct definitions. Hence, the only difference between the groups in the instruction phase was whether or not the TWs were presented in semantic clusters.A week after the instruction phase, the 100-item VKS was 
given again as the posttest. Fortunately, there was no attrition and all 50 participants took the test to discern how the SRP and SUP groups differed in their gains of vocabulary knowledge.

To investigate the effect of semantic clustering on the acquisition of quantitativeand qualitativeknowledge of vocabulary, the scores obtained from the VKS test as pretest and post-test were analyzed using SPSS ANOVA and its non-parametric version Kruskal-Wallis whenever normality requirement was not met. Post hoc tukey and least significance difference (LSD) tests were also employedto locate significant effects atp $<0.05$.

\section{RESULTS}

The mean scores (M) and standard deviations (SD) of both pretest and posttest were calculated for SRP and SUP groups with respect to two quantitative and qualitative dimensions of vocabulary knowledge. As the descriptive statistics in Table 2 indicates, the participants in both SRP and SUP group obtained a higher mean score on the posttest incomparison with their mean scores in the pretest. This improvement is more or less observable for both quantitative and qualitative knowledge of vocabulary. Furthermore, whereas SRP and SUP group obtained almost the same mean scores in quantitative and qualitative pretests, the participants in SRP class outperformed their SUP peers in the posttests. Figure 1 shows this pattern of variance in mean scores graphically.

Table 2. Mean Scores and Standard Deviations of SRP and SUP Group.

\begin{tabular}{|c|c|c|c|c|c|c|c|c|}
\hline & \multicolumn{4}{|c|}{ Quantitative knowledge } & \multicolumn{4}{|c|}{ Qualitative knowledge } \\
\hline & \multicolumn{2}{|c|}{ Pretest } & \multicolumn{2}{|c|}{ Posttest } & \multicolumn{2}{|c|}{ Pretest } & \multicolumn{2}{|c|}{ Posttest } \\
\hline & M & SD & M & SD & M & SD & $\mathrm{M}$ & SD \\
\hline SRP & 213.56 & 21.45 & 376.33 & 48.11 & 20.32 & 6.01 & 71.47 & 16.34 \\
\hline SUP & 211.23 & 19.82 & 301.02 & 56.67 & 21.09 & 7.45 & 45.13 & 12.04 \\
\hline
\end{tabular}

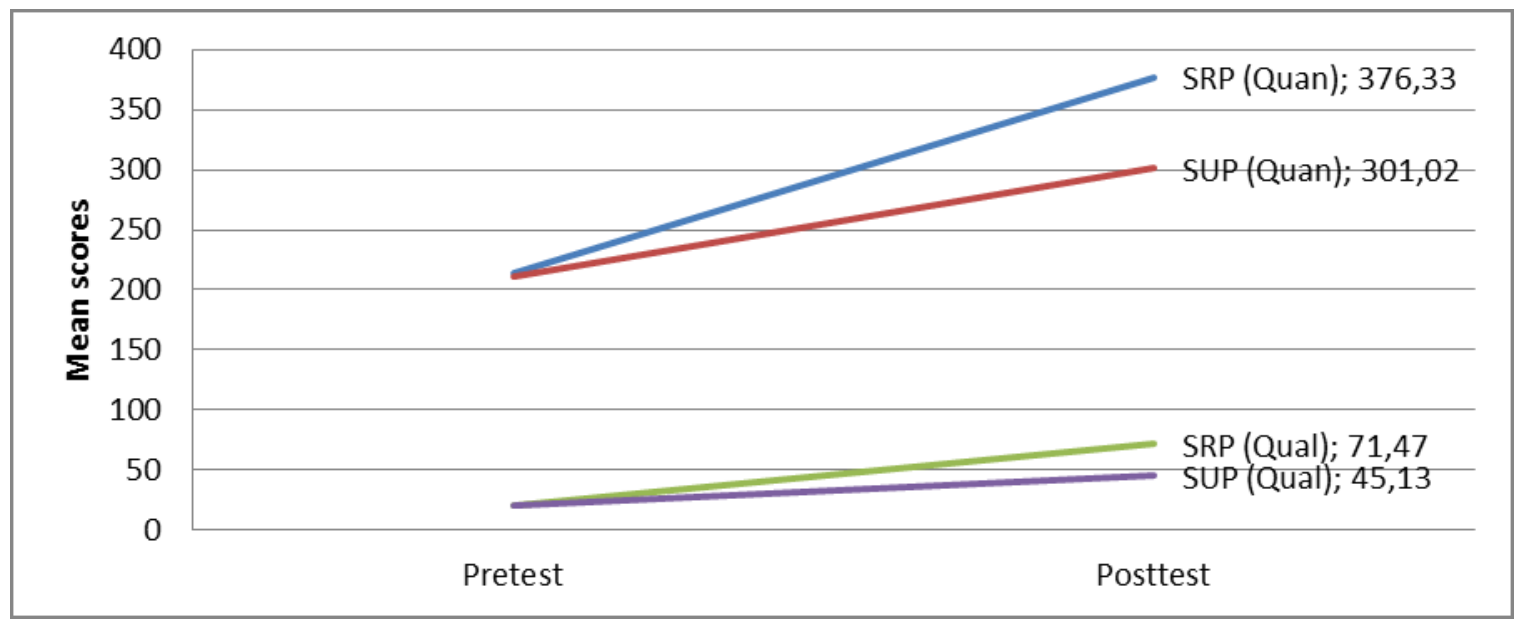

Figure 1. Patterns of Variancein Mean Scoresfor SRP and SUP Group.

To locate statistically significant differences, ANOVA, its non-parametric version Kruskal-Wallis, Post hoc tukey and least significance difference (LSD) tests were used. As Table 3 shows, the mean score differences of the participants in both SRP and SUP group reached statistical significance when their scores in both quantitative and qualitative pretests 
were compared with those of the posttests. As required by a pre-post experimental design, the mean score differences did not yield statistically significant results when the learners' scores in SRP group were compared with the SUP group in the pretests, indicating that the participants had almost the same level of vocabulary knowledge at the time of experiment. Nevertheless, the SRP group significantly did better than the SUP group on both measures of quantitative and qualitative vocabulary knowledge in the posttest which may render different effectiveness of the two methods of vocabulary instruction.

Table 3. In-and Between-groups Comparisons on Pre- and Posttest.

\begin{tabular}{ccccc}
\hline & \multicolumn{2}{c}{ In groups } & \multicolumn{2}{c}{ Between groups } \\
\cline { 2 - 5 } & SRP & SUP & Pretest & Posttest \\
Pretest $\leftrightarrow$ Posttest & Pretest $\leftrightarrow$ Posttest & SRP $\leftrightarrow$ SUP & SRP $\leftrightarrow$ SUP \\
Quantitative & $0.031^{*}$ & $0.046^{*}$ & 0.752 & $0.034^{*}$ \\
Qualitative & $0.010^{*}$ & $0.023^{*}$ & 0.864 & $0.002^{*}$ \\
\hline
\end{tabular}

Note. $*=\mathrm{p}<0.05$

An in-depth analysis of the participants' score variations across different levels of vocabulary knowledge, also revealed that the learners in the SRP class had increasingly progressed from level one, an index of lack of L2 vocabulary knowledge, to level five where they were able to give evidence for their gains in receptive and productive vocabulary knowledge. Although this pattern of progress is also observable in SUP class, its magnitude is obviously less notable (compare Figures 2 and 3).

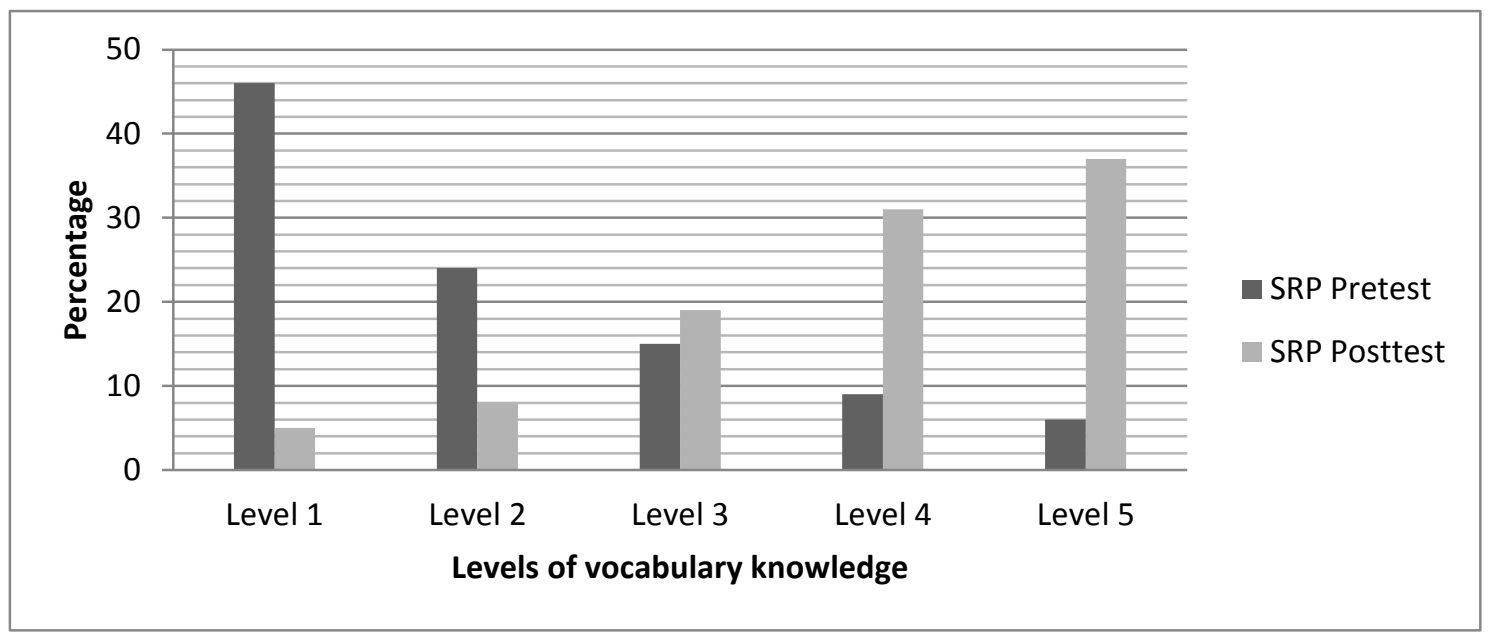

Figure 2. Score Variations across Levels of VocabularyKnowledge for the SRP Group. 


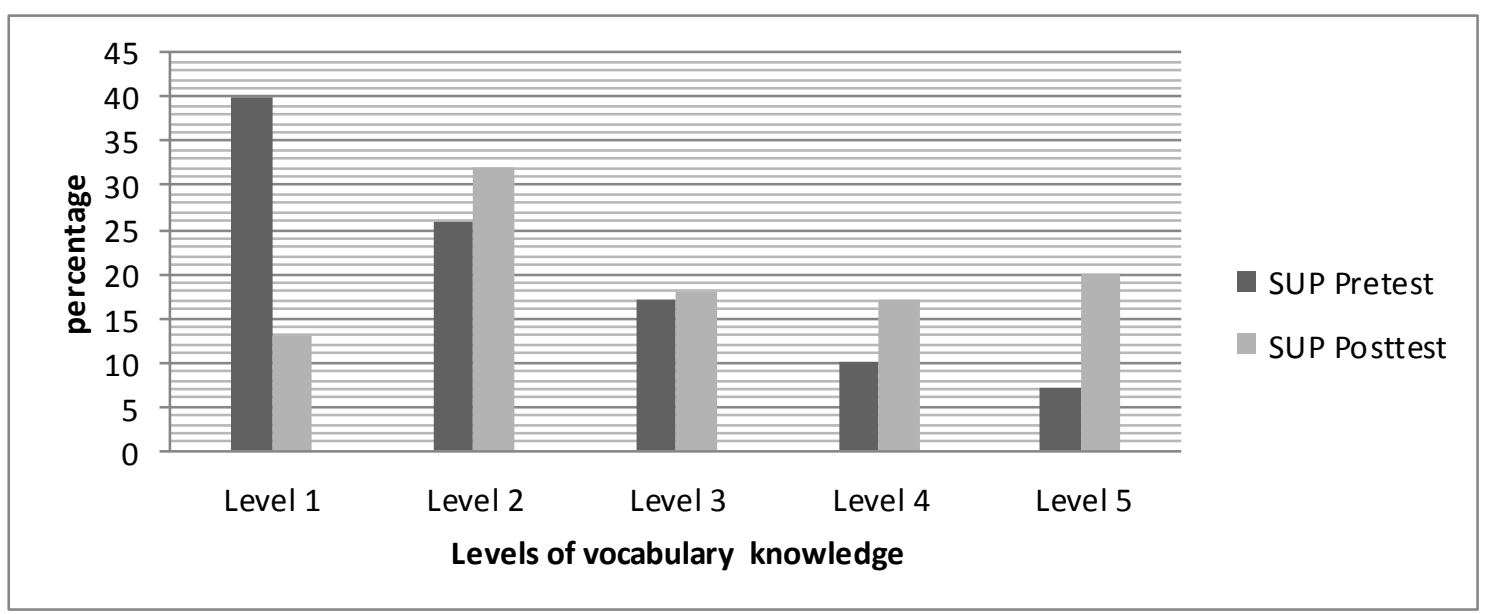

Figure 3. Score Variations across Levels of VocabularyKnowledge for the SUP Group.

\section{DISCUSSION}

The main research question was concerned with the possible effects of semantic clustering the acquisition of quantitative and qualitative vocabulary knowledge. In this regard, three null hypotheses were assumed. The first null hypothesis posited that the participants would not acquirevocabulary knowledge through the SRP method. As the findings revealed, the SRP group performed significantly better in the posttest compared with their scores on the pretest. Therefore, the first hypothesis is rejected, implying that presenting and teaching new vocabulary in semantic clusters may be conducive to significant learning. The second hypothesis assumed that SUP method, that is providing the learners with the TWs in an unrelated fashion, could not lead the learners to significant gains in different aspects of vocabulary knowledge. In this regard, the analysis of variance between the participants' mean scores in the pretest and the posttest revealed that the learners' performance in the SUP group significantly improved in the posttest, refuting the assumption underlying the second hypothesis.

The findings on the third hypothesis was of special importance to this study as they could shed light on whether or not presenting new L2 vocabulary in semantic clusters (i.e. SRP method) could be more effective that the other competing method (i.e. SUP). In this regard, the results showed that the participants in the SRP class significantly outperformed the learners in the SUP class in both quantitative and qualitative measures of vocabulary knowledge. In other words, it seems organizing new words into semantically-related categories could significantly contribute to the learners' success in the acquisition of L2 vocabulary. An in-depth analysis of participants' score variations across the SRP and SUP groups also implied that this method of vocabulary presentation and instruction was probably a better facilitator for the learners in their progress from a basic familiarity with the TWs, to vocabulary knowledge at both reception and production level where they were able to place a new word within its semantic grid and use it in appropriate context. Therefore, as Hashemi and Gowdasiaei $(2005$, p. 356) point out the acquisition of new L2 vocabulary "can be enhanced using some conceptual framework in which words are embedded in meaningful contexts".

The findings of the present study are also in line with the insights form semantic field theory and some models of cognitive psychology such as 'spreading activation model' (Balota\&Lorch, 1986) and 'associative priming' (Anderson, 1995) which assume that concepts 
are stored in and recalled from mind in the form of semantic networks; new words, thus, can be acquired and retrieved from memory more efficiently if they are placed within their related semantic grid. Moreover, as Hashemi and Gowdasiaei (2005) suggest, the SRP learners' advantage over their SUP counterparts might also be related to the fact that learning new words in semantic clusters requires deeper cognitive processing which is in line with 'levelsof-processing theory' (Craik\& Lockhart, 1972) as well.

It is also worth noting that learners' proficiency level might significantly contribute to the effectiveness of semantic clustering. As Wilcox and Medina (2013, p. 1066), exploring the same topic with participants at elementary level, suggests it might be the case that at the novice level, the mind tends to store words that need to be semantically organized "not to receive words that havealready been organized semantically". Therefore, as they conclude, semantic clustering might not be effective (but also interfering) for elementary learners. As the learners progress to intermediate and advanced levels of proficiency, however, the effectiveness of semantic clustering may be more notable. In this regard, Hashemi and Gowdasiaei (2005) comparing lower and upper intermediate learners on the same topic, noted that upper level intermediate participants made greater gains in vocabulary knowledge that their peer lower level ones.

\section{CONCLUSION}

Based on semantic field theory and models of cognitive psychology, the present study provided evidence in support of semantic clustering. The findings indicated that presenting new L2 vocabulary in semantically-related sets may be conducive to significant gains in quantitative and qualitative knowledge of vocabulary. This method of vocabulary presentation and instruction (i.e. SRP) was compared and contrasted with SUP method based on which the participants received the TWs in unrelated sets. It was revealed that while both methods could significantly result in vocabulary acquisition, the SRP method could yield significantly better results.

Therefore, it is recommended that language teachers and material developers consider the possible effects of semantic clustering in preparing their teaching materials. In so doing, teachers may provide their learners with opportunities to learn new L2 vocabulary in semantically-related sets proceeding by appropriate topics. As a classroom activity, teachers may also ask them to organize new words into semantic clusters using hypernyms(as 'advance organizers'). Nevertheless, they should take into account the students' learning styles as they might have different strategies to approach the same task. In addition, it seems language proficiency also plays a major role in the effectiveness of this method. Teacher, thus, need to consider their learners' level of language proficiency and adjust their teaching methods and techniques accordingly. As Nation (2000) suggests, it is also helpful for teachers to take frequency of words into account. Making lexical sets based on their frequency of occurrence, therefore, can be an alternative to semantic clustering. Likewise, there is growing evidence that clustering new words phonologically (i.e. based on sound similarities)can be helpful as well (see Wilcox \& Medina, 2013 in this regard).

As any piece of research, this study was also limited in a number of ways. Firstly, only intermediate level learners took part in this study. The findings of the study could be more generalizable if the sample also contained participants at elementary and advanced levels of language proficiency. Secondly, the time interval between the instruction and assessment phase was only one week. The findings might vary if longer periods of time were taken into account. Finally, the present study mainly relied on quantitative measures of vocabulary knowledge which may not be perfect indicators of the participants' latent knowledge. It is 
recommended that interested researchers probe the same issue employing participants at various levels of language proficiency. In addition, adding qualitative measurement tools can improve the reliability of the findings and validity of the interpretations. Finally, embarking on longitudinal studies in classroom settings using different sets of semantically-related and unrelated words can be fruitful lines of future research.

\section{References}

[1] Anderson, J.R. (1995).Cognitive Psychology and its Implications.New York: W.H. Freeman, 4th ed.

[2] Ang, I. (2014). Rethinking the role of context and definition in second language vocabulary acquisition (SLVA): An assimilation via a cognitive model of concept formation. International Journal of Research Studies in Language Learning, 3(1), 33-50. http://dx.doi.org/10.5861/ijrsll.2013.515

[3] Baddeley, A. D. (1990). Human Memory Theory and Practice.Erlbaum, Hillsdale, NJ.

[4] Balota, D.A., \& R.F. Lorch. (1986). Depth of automatic spreading activation: Mediated priming effects in pronunciation but not in lexical decision.Journal of Experimental Psychology: Learning, Memory, and Cognition, 12, 336-45.

[5] Choo, L.B., Lin, D.T.A., \&Pandian, A. (2012). Language learning approaches: A review of research on explicit and implicit learning in vocabulary acquisition. Procedia: Social and Behavioral Sciences, 55, 852-860. doi: 10.1016/j.sbspro.2012.09.572

[6] Craik, F.I.M., \& Lockhart, R. S. (1972). Levels of processing: A framework for memory research.Journal of verbal Learning and Verbal Behavior, 11, 671-84.

[7] Erten, I. H., \&Tekin, M. (2008). Effects on vocabulary acquisition of presenting new words in semantic sets versus semantically unrelated sets.System 36 (3), 407-422.

[8] Finkbeiner, M., \&Nicol, J. (2003). Semantic category effects in second language word learning. Appl. Psycholinguistics 24 (3), 283-369.

[9] Hashemi, M., \&Gowdasiaei, F. (2005). An attribute-treatment interaction study: lexicalset versus semantically-unrelated vocabulary instruction. RELC Journal, 36, 341-361.

[10]Heidari-Shahreza, M. A., \&Tavakoli, M. (2012). The effects of repetition and L1 lexicalization on incidental vocabulary acquisition by Iranian EFL Learners. The Language Learning Journal, 40, 1-16. doi:10.1080/09571736.2012.708051

[11]Heidari-Shahreza, M. A., Moinzadeh, A., Barati, H. (2014a).The effect of exposure frequency on incidental vocabulary acquisition. GEMA Online Journal of Language Studies, 14 (1), 43-55.

[12]Heidari-Shahreza, M. A., Moinzadeh, A., Barati, H. (2014b).A comparative investigation into effects of L1 lexicalization and cultural loadedness on incidental vocabulary acquisition and retention. International Journal of Research Studies in Language Learning, 3(5), 83-96.

[13]Heidari-Shahreza, M. A. (2014). The development of productive knowledge of vocabulary through implicit exposure: Non-lexicalized words in focus. Journal of Applied Linguistics and Language Research (JALLR), 1 (1), 1-11.

[14]Hoshino, Y.(2010). The categorical facilitation effects on L2 vocabulary learning in a classroom setting. RELC Journal, 41, 301e312. 
[15]Hunt, R. R., \& Elliot, J. M. (1980). The role of nonsemantic information in memory: orthographic distinctiveness effects on retention. Journal ofExperimental Psychology: General, 109, 49-74.

[16]Keiffer, M. J., \&Lesaux, N.K. (2012). Knowledge of words, knowledge about words: Dimensions of vocabulary in first and second language learners in sixth grade. Reading and Writing 25, 347-373.Doi: 10.1007/s11145-010-9272-9

[17]Lehrer, A. (1974). Semantic Fields and Lexical Structure.North-Holland, Amsterdam.

[18]Min, H-T. (2008). EFL vocabulary acquisition and retention: reading plus vocabulary enhancement activities and narrow reading. Language Learning, 58(1), 73-115.

[19] Nation, I. S. P. (2001). Learning Vocabulary in another Language. Cambridge: Cambridge University Press.

[20]Nation, I.S.P., 2000. Learning vocabulary in lexical sets: dangers and guidelines. TESOL J. 9 (2), 6-10.

[21]Nation, I. S. P. (2013). Vocabulary acquisition in second language acquisition. In C. A. Chapelle (Ed.), The Encyclopedia of Applied Linguistics. Oxford: Blackwell Publishing Ltd. doi: 10.1002/9781405198431.wbeal1265

[22]Nida, E.A. (1975). Componential analysis of meaning: an introduction to semantic structures. Mouton, The Hague.

[23]Papathanasiou, E. (2009). An investigation of two ways of presenting vocabulary.ELT Journal, 63 (4), 313-322.

[24]Rott, S. (2013). Incidental vocabulary acquisition. In C. A. Chapelle (Ed.), The Encyclopedia of Applied Linguistics. Oxford: Blackwell Publishing Ltd. doi: 10.1002/9781405198431.wbea10531

[25] Schneider, V., Healy, A., \& Bourne, L.(2002). What is learned under difficult conditions is hard to forget: contextual interference effects in foreign vocabulary acquisition, retention, and transfer. Journal of Memory and Language, 46, 419-440.

[26] Stoller, F., \&Grabe, W.(1995). Implications for L2 vocabulary acquisition and instruction from L1 vocabulary research. In: Huckin, T., Haynes, M., Coady, J. (Eds.), Second Language Reading and Vocabulary Learning. Ablex Publishing Corporation, Norwood, NJ, pp. 24-45.

[27] Tinkham, T.(1993). The effect of semantic clustering on the learning of second language vocabulary.System 21 (3), 371-380.

[28] Tinkham, T.(1997). The effects of semantic and thematic clustering on the learning of a second language vocabulary.Second Language Research, 13 (2),138-163.

[29]Waring, R.(1997). The negative effects of learning words in semantic sets: a replication. System, 25 (2), 174-261.

[30]Webb, S. (2007). The effects of repetition on vocabulary knowledge.Applied Linguistics, 28(1), 46-65.

[31] Webb, S. (2013). Depth of vocabulary knowledge. In C. A. Chapelle (Ed.), The Encyclopedia of Applied Linguistics. Oxford: Blackwell Publishing Ltd. doi: 10.1002/9781405198431.wbeal1325

[32]Wilcox, A. \& Medina, A. (2013). Effects of semantic and phonological clustering on L2 vocabulary acquisition among novice learners.System 41, 1056-1069 